\title{
Preparation of Hydrogel Chitosan Co-Polyacrilamide Crosslinked Glutaraldehyde
}

\author{
Halimahtussadiyah Ritonga ${ }^{1}$, Muhammad Nurdin², Fransiskus S. Rembon ${ }^{3}$, L.O.A.N. \\ Ramadhan $^{4}$, Fitriana ${ }^{5}$ \\ $1,2,4,5$ Departement of Chemistry, Faculty of Mathematical and Natural Science, \\ Universitas Halu Oleo, Indonesia. 93132 \\ ${ }^{3}$ Department of Soil Science, Faculty of Agriculture, Universitas Halu Oleo, Indonesia. 93132 \\ \{halimahhalimah124@yahoo.ac.id $\left.{ }^{1}\right\}$
}

\begin{abstract}
Chitosan co-polyacrylamide hydrogel crosslinked has been prepared by glutaraldehyde to obtain the unique material as soil remediation for agriculture applications which play a role in water storage to increase plant fertility. In this study, we examine the compositions effect of hydrogel material, the optimum concentration of glutaraldehyde as crosslinker, and hydrogel properties. Based on the results, the hydrogel successfully synthesized through chemical crosslinking methods that the $0.53 \mathrm{~g}, 1.06 \mathrm{~g}$, and $1.59 \mathrm{~g}$ of glutaraldehyde to $(0.9: 5.1),(1.2: 4.8)$ and $(1.5: 4.5)$ grams of chitosan and acrylamide were used to increase the degree of swelling properties KKPAG105 396.17\% (0.9:5.1) and KKPAG205 262.51\% (1.2:4.8), respectively. Subsequently, Fourier-transform infrared spectroscopy (FTIR) was characterized to identify functional groups of hydrogel material shows that the existing functional groups of $\mathrm{OH}$ overlapping with $\mathrm{NH}$ at $3446.72 \mathrm{~cm}-1$ from chitosan, $\mathrm{C}=\mathrm{O}$ at $1633.49 \mathrm{~cm}-1$ from glutaraldehyde, and $\mathrm{C}=\mathrm{N} 1433.11 \mathrm{~cm}-$ 1 from polyacrylamide. In addition, morphologically has been identified by Scanning Electron Microscope (SEM) that the chitosan co-polyacrylamide hydrogel crosslinked by glutaraldehyde which is pores formed for passing water absorption. Based on this study, we can be able to utilize in regeneration of soil mining area.
\end{abstract}

Keywords: Hydrogel, Glutaraldehyde, Crosslinking, Soil Conditioner, Chitosan, Acrylamide, Swelling, Soil mining area.

\section{Introduction}

At this recent years industrial field has tried to develop material that is useful in agriculture especially in dealing with food needs and for regeneration of soil mining area. One of the materials developed in the agriculture field is super absorbent hydrogel polymers as soil conditioner. Hydrogel is a material that is capable of improving soil conditioner because it has the ability to hold water and nutrients and can support plant growth by improving soil properties [1]. Polymeric material for preparing hydrogels must swell and maintain the water fraction in its structure, but not soluble in water. Acrylamide (AAM) is one type of hydrophilic monomer which is the most popular raw material for the manufacture of polyacrylamide superabsorbent polymers (PAAM) [2]. Polyacrylamide polymers (PAAM) are being developed as a base 
material for new biomaterials. In addition it is used as PAAM hydrogel as absorbent material (absorbent). However, PAAM has a weakness in absorbing water (swelling limited) and a homopolymer with relatively low physical properties, therefore its application is also limited [3]. One alternative that can be used to deal with these problems is the graft polymerization process between natural polymers, for example chitosan against polyacrylamide. The selection of chitosan due to its nature biodegradable, not polluting the environment, biocompatible, and its molecular structure can be easily modified, that's the reason chitosan can be used in preparing hydrogels [4].

Synthesis of polyacrylamide grafted chitosan-based hydrogel can be carried out by crosslinking method. Crosslinking agents in the manufacture of hydrogels that can be used include those from aldehydes, urea derivatives, and carboxylic acids [5]. One of the studies conducted by Dwimitriv et al. (2015) [6] has synthesized polyacrylamide hydrogels using glutaraldehyde as a crosslinking agent. Modifications with other polymers on the manufacture of chitosan hydrogels can also be done, such as by Sadeghi, et al. (2011) [7] which synthesizes hydrogels by grafting chitosan using acrylonitrile and acrylic acid monomers and ammonium persulfate (APS) and N, N'-methylenbis acrylamide initiators (MBA) as a crosslinking agent. Based on this description, this study focused on the effect of the composition of the glutaraldehyde crosslinking agent to determine the characteristics of the superabsorbent polymers produced and obtain a superabsorbent with a high ability to absorb water.

\section{Material and Methods}

\section{1 Material}

Materials used in making hydrogel chitosan crosslinked glutaraldehyde: Chitosan (synthesis of chitosan from shrimp skin by Marganov method, 2003) [8], Acetic Acid, Acrylamide, Benzoyl Peroxide and Glutaraldehyde. each ingredient is made according to the desired concentration.

\section{2 Synthesis of Chitosan Co-Polyacrylamide}

Preparing hydrogels begins with a polymerization reaction of chitosan co-polyacrylamide which is 15,20 and $25 \%$ chitosan which is each dissolved in acetic acid $2 \%$ to $6 \mathrm{~g}$ mass acrylamide inserted in a two neck round bottom flask, added with 0.5 grams benzoyl peroxide as an initiator, and stirred over the heater while nitrogen gas is poured for 2 hours at a temperature of $60-70{ }^{\circ} \mathrm{C}[3]$. Variations in the composition of prepared hydrogels can be seen in Table 1.

Table 1. The composition of chitosan composition against acrylamide

\begin{tabular}{cc}
$\begin{array}{c}\text { chitosan } \\
(\mathbf{g})\end{array}$ & $\begin{array}{c}\text { acrylamide } \\
(\mathbf{g})\end{array}$ \\
\hline 0.9 & 5.1 \\
1.2 & 4.8 \\
1.5 & 4.5 \\
\hline
\end{tabular}




\subsection{Synthesis Chitosan co-Polyacrylamide Cross-Linked Glutaraldehyde}

The suspension of chitosan co-polyacrylamide formed is added with glutaraldehyde as a crosslinker with a comparison of variations in the number of different masses $(0.53 ; 1.06 ; 1.59$ grams) and the reaction was carried out for 1 hour while stirring to form a gel. Table 2. Showing comparison of the composition of the suspension of chitosan co-polyacrylamide and glutaraldehyde.

Table 2. The suspension composition of the comparison co-polyacrylamide chitosan and glutaraldehyde.

\begin{tabular}{ccc}
\hline Sample Code & $\begin{array}{c}\text { Chitosan: Acrylamide } \\
(\mathbf{g})\end{array}$ & $\begin{array}{c}\text { Glutaraldehyde } \\
(\mathbf{g})\end{array}$ \\
\hline KKPAG105 & $0.9: 5.1$ & 0.53 \\
KKPAG110 & $0.9: 5.1$ & 1.06 \\
KKPAG115 & $0.9: 5.1$ & 1.59 \\
KKPAG205 & $1.2: 4.8$ & 0.53 \\
KKPAG210 & $1.2: 4.8$ & 1.06 \\
KKPAG215 & $1.2: 4.8$ & 1.59 \\
KKPAG305 & $1.5: 4.5$ & 0.53 \\
KKPAG310 & $1.5: 4.5$ & 1.06 \\
KKPAG315 & $1.5: 4.5$ & 1.59 \\
\hline
\end{tabular}

\subsection{Characterization of Hydrogels}

\section{a. Functional Groups Test Using FTIR (Fourier Transform Infra Red)}

Characterization using FTIR aims to determine the functional groups contained in the hydrogel. Grain-shaped solid footage is measured in the spectrum by mixing with $\mathrm{KBr}$ and made pellet. The sample is inserted into the IR frame and the spectrum is analyzed and made. Measurements are carried out at room temperature with a resolution of $8.0 \mathrm{~cm}^{-1}$. FTIR spectrum was used to analyze the functional groups of chitosan, chitosan co-polyacrylamide, and chitosan co-polyacrylamide cross-linked glutaraldehyde.

\section{b. Morphological Test Using SEM (Scanning Electron Microscope)}

Characterization using SEM aims to determine the surface and pore shape of the hydrogel which will affect the absorption properties of the hydrogel [9].Tests are carried out by means of footage placed in alayer carbon-conductive and coated with $60 \%$ gold and $40 \%$ palladium with a sputtercoater at a current of $35 \mathrm{~mA}$ for 1 minute. Operating conditions are carried out at a voltage acceleration of $10 \mathrm{kV}$ and a magnification of $5.000 \mathrm{x}$.

\subsection{Hydrogel Testing}

\section{a. Hydrogel Swelling Test}

Sample $(0.1 \mathrm{~g})$ were immersed in $100 \mathrm{~mL}$ of distilled water. The mixture is then filtered using filter paper for 10 minutes. The amount of absorbed water is calculated as follows: 
(1)

$\%$ Swelling $=\frac{\text { Gs }-\mathrm{Gi}}{\mathrm{Gi}} \times 100 \%$

Where Gs is the weight swelling of the hydrogel and Gi is the initial weight of the polymer sample.

\section{b. Degree of Crosslinking Hydrogel}

The dry weight of the resulting hydrogel is weighed. Then the hydrogel is soaked in distilled water for 24 hours. After immersion, the hydrogel is heated at a temperature of $60^{\circ} \mathrm{C}$ to dry. The dry weight of the hydrogel film after immersion is determined using an analytical balance. The degree of crosslinking can be determined by:

$$
\% \mathrm{DC}=\frac{\mathrm{w}_{\mathrm{g}}}{\mathrm{w}_{0}} \times 100
$$

Where $\mathrm{W}_{\mathrm{g}}$ is the weight of crosslinkedglutaraldehyde hydrogel after immersion and $\mathrm{W}_{0}$ is the weight of the dry hydrogel before immersion.

\section{Result and Discussion}

\subsection{Synthesis of Chitosan co-Polyacrylamide Crosslinked Glutaraldehyde}

Synthesis of chitosan co-polyacrylamide by chitosan copolymerization method which will first interact with the initiator of benzoyl peroxide before interacting with a mixture of acrylamide and glutaraldehyde monomer as a crosslinking agent. The distribution of nitrogen gas continues to be carried out during the reaction process because oxygen can inhibit the formation of copolymers through peroxide formation and instead encourage the formation of homopolymers[10]. The addition of gutaraldehyde as a crosslinking agent can influence the mechanical properties of the hydrogels produced [11]. The composition of glutaraldehyde can influence the crosslinking reaction between the chitosan co-polyacrylamide hydrogel and the crosslinking agent used. Figure 1. Shows the synthesis result hydrogel chitosan copolyacrylamide crosslinked by glutaraldehyde.

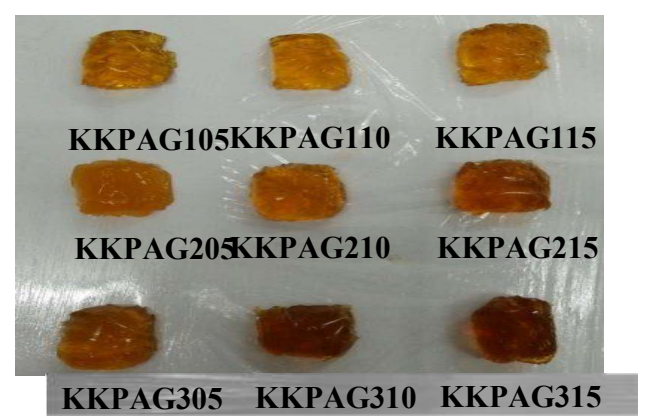

Fig. 1.Hydrogel Chitosan Co-PolyacrilamideCrosslinkedGlutaraldehyde 


\subsection{Hydrogel Characterization}

\section{a. Functional Groups Test Using FTIR (Fourier Transform Infra Red)}

Analysis FTIR was used to identify functional groups contained in hydrogels. Spectra of FTIR chitosan co-polyacrylamide hydrogel bound to glutaraldehyde can be seen in Figure 2.

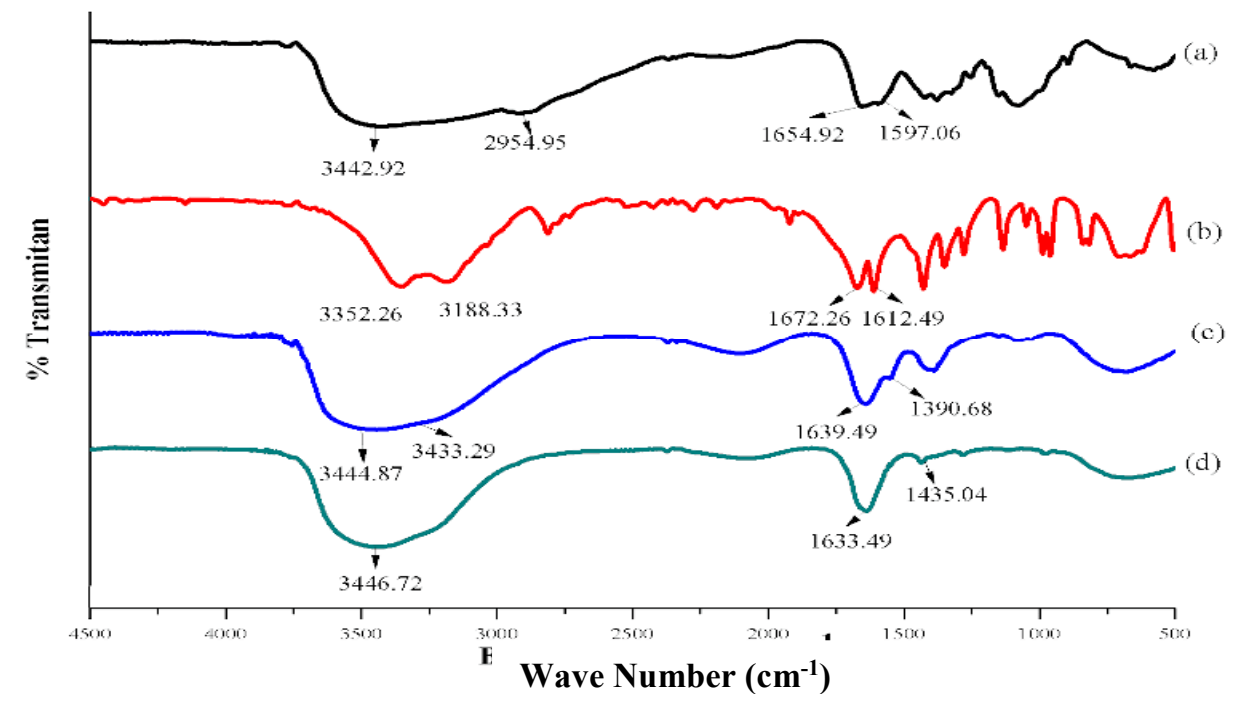

Fig 2. FTIR Spectrum (a) Chitosan (b) Acrylamide (c) Chitosan co-Polyacrylamide (d) Chitosan CoPolyacrylamide Crosslinked Glutaraldehyde

Table 3. FTIR absorption peak Chitosan, acrylamide, chitosan co-polyacrylamide, chitosan co-polyacrylamide Crosslinked Glutaraldehyde

\begin{tabular}{ccccc}
\hline \multirow{2}{*}{$\begin{array}{c}\text { Functional } \\
\text { Groups }\end{array}$} & Chitosan & acrylamide & $\begin{array}{c}\text { Whitosan co- } \\
\text { polyacrylamide }\end{array}$ & $\begin{array}{c}\text { Chitosan } \\
\text { co-polyacrylamide } \\
\text { Glutaraldehyde }\end{array}$ \\
\cline { 2 - 5 } & 3442.92 & 3352.26 & 3444.87 & 3446.72 \\
$\mathrm{OH}$ & 3423.43 & 3188.33 & 3433.29 & 3446.72 \\
$\mathrm{NH}\left(-\mathrm{NH}_{2}\right)$ & 2922.16 & 2812.21 & - & - \\
$\mathrm{CH}\left(-\mathrm{CH}_{2}\right)$ & 1654.92 & 1672.26 & 1639.49 & 1633.49 \\
$\mathrm{C}=\mathrm{O}(-$ & 1327.03 & 1350.17 & 1390.68 & 1433.11 \\
$\mathrm{NHCOCH})$ & 1597.06 & 1612.49 & 1390.68 & 1435.04 \\
$\mathrm{CN}(-\mathrm{NHCOCH}$ & \\
$\mathrm{NH}\left(\mathrm{R}-\mathrm{NH}_{2}\right)$ & 1151.50 & 1136.07 & 1134.14 & 1188.15 \\
$\mathrm{CO}(-\mathrm{COC}-)$ & 1080.14 & 1049.28 & 1082.07 & 1082.07 \\
$\mathrm{CO}(-\mathrm{COC}-)$ & & & & \\
\hline
\end{tabular}

Identification of the structure of chitosan-co-polyacrylamide crosslink glutaraldehyde is done using FTIR. Based on this picture, it can be seen that there is an absorption peak in the area of $3446.72 \mathrm{~cm}^{-1}$ which indicates the presence of $\mathrm{OH}$ groups. This $\mathrm{OH}$ group originates from $-\mathrm{OH}$ in those found in the chitosan chain. Uptake at $1633.49 \mathrm{~cm}^{-1}$ and $1435.04 \mathrm{~cm}^{-1}$ is a 
stretching vibration of $\mathrm{C}=\mathrm{O}$ and $\mathrm{NH}$ which indicates that chitosanco-polyacrylamide glutaraldehydehas has been successfully synthesized.

\section{c. Hydrogel Morphology Analysis Using Scanning Electron Microscopy (SEM)}

Analysis of morphological characterization of hydrogels was carried out using Scanning Electron Microscopy (SEM), to determine the surface morphology of hydrogel chitosan copolyacrylamide crosslinked glutaraldehyde that successfully synthesized. SEM characterization was only carried out on hydrogels which had the degree of highest swelling and the lowest swelling of hydrogel with a magnification of 5000x. they can be seen in Figure 3.
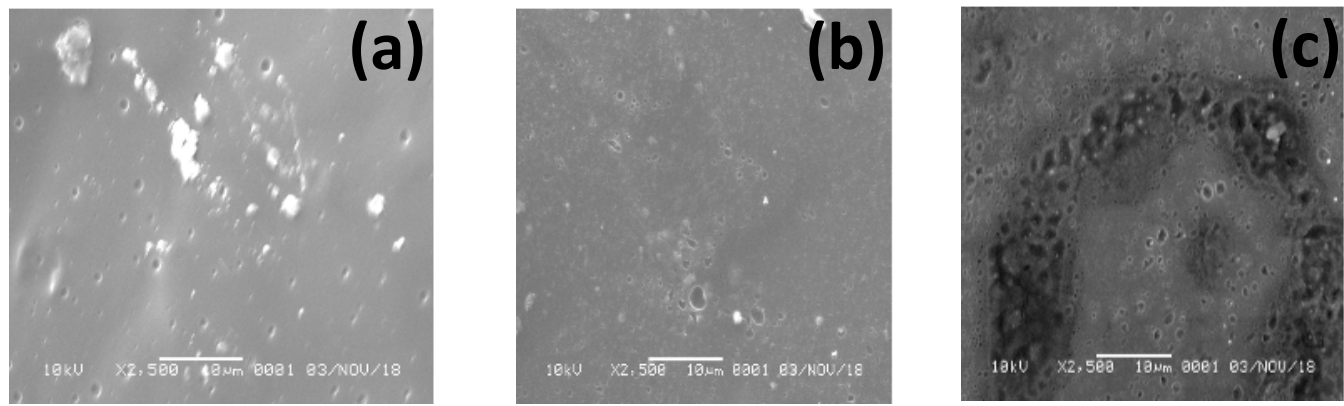

Fig3. SEM various comparisons of chitosan concentration: acrylamide: glutaraldehyde (a) KKPAG105,

(b) KKPAG205 and (c) KKPAG315

Figure 3 (a) showed the morphology of KKPAG105, the results showing the formation of smooth and pores surface morphology of the hydrogels. Figure (b) showing the morphology of KKPAG205, it appears that the formation of pores and surface is smoother than figure (a). Figure (c) shows the morphological results of KKPAG315, the surface of the hydrogel has a dense cavity size compared to figures (a) and (b). The shape of this cavity results in a low water absorption capacity. This is caused by the large number of crosslinking agents and the increasing crosslinking rate of the hydrogels.

\subsection{Swelling Power and Crosslinking Degree Test of Hydrogel Chitosan Co- Polyacrylamide}

The character of swelling hydrogels is also influenced by the chemical structure of the hydrogel. Hydrogels containing hydrophilic groups are better than hydrogels containing hydrophobic groups[12]. Chitosan co-polyacrylamide hydrogel polymer swelling on each variation of chitosan composition and variation of glutaraldehyde concentration. Table 4 . showed the ratio of swelling hydrogel.

Table 4.Ratio Swelling to the composition of the hydrogel

\begin{tabular}{ccccc}
\hline $\begin{array}{c}\text { Sample } \\
\text { Code }\end{array}$ & $\begin{array}{c}\text { Glutaraldehyde } \\
\text { (g) }\end{array}$ & $\begin{array}{c}\text { Initial Weight } \\
\text { (Gi) (g) }\end{array}$ & $\begin{array}{c}\text { Weight after } \\
\text { Sweeling (Gs) (g) }\end{array}$ & $\begin{array}{c}\text { \% } \\
\text { Swelling }\end{array}$ \\
\hline KKPAG105 & 0.53 & 3.007 & 14.92 & $\mathbf{3 9 6 . 1 7}$ \\
KKPAG110 & 1.06 & 3.006 & 7.6 & 152.82 \\
KKPAG115 & 1.59 & 3.000 & 6.23 & 107.66 \\
KKPAG205 & 0.53 & 3.004 & 10.89 & $\mathbf{2 6 2 . 5 1}$
\end{tabular}




\begin{tabular}{llllc} 
KKPAG210 & 1.06 & 3.002 & 6.85 & 128.18 \\
KKPAG215 & 1.59 & 3.005 & 4.52 & 50.41 \\
KKPAG305 & 0.53 & 3.009 & 8.41 & 179.49 \\
KKPAG310 & 1.06 & 3.006 & 5.43 & 80.63 \\
KKPAG315 & 1.59 & 3.005 & 3.76 & $\mathbf{2 5 . 1 2}$ \\
\hline
\end{tabular}

Percent of crosslinked degrees is one of the parameters commonly used in testing crossbound strength in polymeric hydrogel tissue [13]. Percentages of crosslinking obtained are in Table 5.

Table 5. Degree of Crosslinking to The Composition of The Material

\begin{tabular}{ccccc}
\hline $\begin{array}{c}\text { Code of } \\
\text { Sample }\end{array}$ & $\begin{array}{c}\text { Glutaraldehyde } \\
(\mathbf{g})\end{array}$ & $\begin{array}{c}\text { Weight } \\
\text { before } \\
\text { soaking }(\mathbf{g})\end{array}$ & $\begin{array}{c}\text { Dry Weight } \\
\text { after Soaking } \\
\mathbf{( g )}\end{array}$ & $\begin{array}{c}\text { \% Degree of } \\
\text { Crosslink }\end{array}$ \\
\hline KKPAG105 & 0.53 & 2.01 & 0.23 & $\mathbf{1 1 . 7 9}$ \\
KKPAG110 & 1.06 & 2.03 & 0.61 & 29.55 \\
KKPAG115 & 1.59 & 2.01 & 1.03 & 51.24 \\
KKPAG205 & 0.53 & 2.02 & 0.23 & $\mathbf{1 1 . 3 8}$ \\
KKPAG210 & 1.06 & 2.01 & 1.09 & 54.22 \\
KKPAG215 & 1.59 & 2.01 & 1.12 & 55.72 \\
KKPAG305 & 0.53 & 2.02 & 0.82 & 40.59 \\
KKPAG310 & 1.06 & 2.02 & 0.93 & 46.03 \\
KKPAG315 & 1.59 & 2.01 & 1.35 & $\mathbf{6 7 . 1 6}$ \\
\hline
\end{tabular}

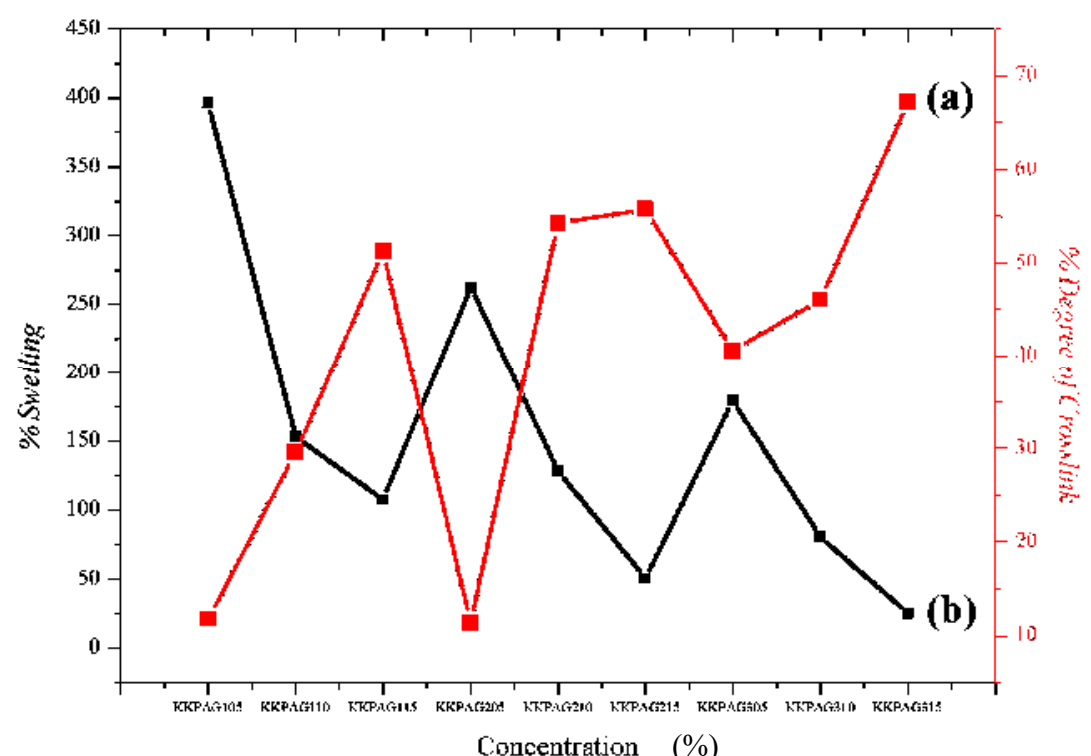


Fig 4. Profile The Relationship of The Comparison of Glutaraldehyde Composition to (a) Crosslinking Degree and (b)Swelling Degree

Figure 4 (b). shows swelling degree of each variation composition and concentration. The highest leveling rate was found in the composition of KKPAG105 (0.9 chitosan: 5.1 acrylamide) $396.17 \%$ and KKPAG205 (1.2 chitosan: 4.8 acrylamide) $262.51 \%$ with the addition of $0.53 \mathrm{~g}$ glutaraldehyde respectively. Meanwhile swelling degree that was low in the composition of KKPAG315 (1.5 chitosan: 4.5 acrylamide) $25.12 \%$ with the addition $1.59 \mathrm{~g}$ of glutaraldehyde. The magnitude of the swelling of the hydrogel is influenced by the ionic interaction between the crosslinked group and crosslink density[14]. Figure 4. shows that the tendency of crosslinking degrees varies by concentration. Asohok and Rana (2010)[15] state that increasing the degree of crosslinking can reduce the degree of sweelling hydrogels. The highest degree of crosslinking was obtained in the composition of KKPAG315 with the addition of glutraldehyde variation of $1.59 \mathrm{~g}$, but the degree swelling possessed was lower. Where as for the variation of KKPAG105 and KKPAG205 with the addition of variations of glutaraldehyde $0.53 \mathrm{~g}$ it has a smaller degree of crosslinking compared to the variation of other compositions, causing a greater degree of swelling. The amount of chitosan composition will cause more carbonyl groups to react with the amine group in chitosan co-polycarylamide polymer therefore the process of forming crosslinks is faster[16]. The increased concentration of glutaraldehyde causes crosslinking degrees to increase but decreases the degree of swelling[17]. The increasing content of crosslinking agents will accelerate the achievement of gel points and gel content, but can reduce the mechanical stability of the hydrogel.

\section{Conclusion}

The success of syntheses is known based on the characterization of FTIR functional group analysis. SEM was used to confirm the formation of pores in the manufacture of copolyacrylamide chitosan hydrogels which were modified by the addition of binding agents to a variety of compositions, to achieve the highest swelling value based on the formed pore. This makes it possible to reduce the amount of wasted water (control released) at the time of application as a soil conditioner. Control releases also play a role in regulating nutrition because of the water content that is always fulfilled at all times. The experimental results show that this product has an excellent water retention capacity so that it has the potential to be used as a soil conditioner for agricultural applications and for regeneration of mining area.

\section{References}

[1] G. Jamnická et al., "The soil hydrogel improved photosynthetic performance of beech seedlings treated under drought," Plant, Soil Environ., vol. 59, no. 10, pp. 446-451, 10.17221/170/2013PSE (2013)

[2] A. S. Azidi Irwan, Sunardi, "Polimer Superabsorben Berbasis Akrilamida (AAM) Tercangkok Pati Bonggol Pisang (Musa paradisiaca)," Pros. Semirata FMIPA Univ. Lampung, pp. 45-54, (2013)

[3] E. M. Ahmed, "Hydrogel: Preparation, characterization, and applications: A review.," J. Adv. Res., vol. 6, no. 2, pp. 105-21,10.1016/j.jare.2013.07.006 (2015)

[4] S. Yu et al., "A novel pH-induced thermosensitive hydrogel composed of carboxymethyl chitosan and poloxamer cross-linked by glutaraldehyde for ophthalmic drug delivery," Carbohydr. Polym., vol. 155, pp. 208-217, 10.1016/j.carbpol.2016.08.073 (2017)

[5] D. Ciolacu, A. M. Oprea, N. Anghel, G. Cazacu, and M. Cazacu, "New cellulose-lignin hydrogels 
and their application in controlled release of polyphenols," Mater. Sci. Eng. C, vol. 32, no. 3, pp. 452-463, 10.1016/j.msec.2011.11.018 (2012)

[6] I. Dmitriev, I. Kuryndin, N. Bobrova, and M. Smirnov, "Swelling behavior and network characterization of hydrogels from linear polyacrylamide crosslinked with glutaraldehyde," Mater. Today Commun., vol. 4, pp. 93-100, 10.1016/j.mtcomm.2015.06.005 (2015)

[7] M. Sadeghi and M. Yarahmadi, "Synthesis and characterization of superabsorbent hydrogel based on chitosan-g-poly ( acrylic acid-co- acrylonitrile )," African J. Biotechnol., vol. 10, no. 57, pp. 12265-12275, 10.5897/AJB11.925 (2011)

[8] N. Asni, M. A. Saadilah, and D. Saleh, "Optimasi Sintesis Kitosan dari Cangkang Kepiting Sebagai Adsorben Logam Berat Pb(II)Asni, N., Saadilah, M. A., \& Saleh, D. (2014). Optimasi Sintesis Kitosan dari Cangkang Kepiting Sebagai Adsorben Logam Berat Pb(II). Jurnal Fisika Dan Aplikasinya, 15(1)," J. Fis. dan Apl., vol. 15, no. 1, pp. 18-25, 2014.

[9] H. Chavda, I. Modhia, R. Patel, and C. Patel, "Preparation and characterization of superporous hydrogel based on different polymers," Int. J. Pharm. Investig., vol. 2, no. 3, p. 134, 10.4103/2230-973x.104396 (2012)

[10] T. Kurniadi and Z. A. MAS'UD, "Kopolimerisasi Grafting Monomer Asam Karakteristiknya," (2010)

[11] E. Budianto, S. P. Muthoharoh, and N. M. Nizardo, "Effect of Crosslinking Agents, pH and Temperature on Swelling Behavior of Cross-linked Chitosan Hydrogel," Asian J. Appl. Sci., no. October, pp. 2321-0893, (2015)

[12] Q. Chai, Y. Jiao, and X. Yu, "Hydrogels for Biomedical Applications: Their Characteristics and the Mechanisms behind Them," Gels, vol. 3, no. 1, p. 6, 10.3390/gels3010006 (2017)

[13] L. Kenne et al., "Modification and cross-linking parameters in hyaluronic acid hydrogels Definitions and analytical methods," Carbohydr. Polym., vol. 91, no. 1, pp. 410-418, 10.1016/j.carbpol.2012.08.066 (2013)

[14] Rizka Nurbiati dan Ahmad Zulfikar, "Preparasi Dan Karakterisasi Kitosan- Dalam Sediaan Film Yang Mengandung Verapamil Hidroklorida," (2015)

[15] A. K. Tiwary and V. Rana, "Cross-linked chitosan films: effect of cross-linking density on swelling parameters.," Pak. J. Pharm. Sci., vol. 23, no. 4, pp. 443-8 (2010)

[16] D. R. Rohindra, A. V Nand, and J. R. Khurma, "Swelling properties of chitosan hydrogels 1 INTRODUCTION 3 RESULTS AND DISCUSSION," South Pacific J. Nat. Appl. Sci., vol. 22, no. 1, pp. 32-35, http://dx.doi.org/10.1071/SP04005 (2004)

[17] S. Distantina, Rochmadi, M. Fahrurrozi, and Wiratni, "Preparation and characterization of glutaraldehyde-crosslinked kappa carrageenan hydrogel," Eng. J., vol. 17, no. 3, pp. 57-66, 10.4186/ej.2013.17.3.57 (2013) 